\title{
BIOANALYTICAL METHOD DEVELOPMENT AND VALIDATION FOR THE ESTIMATION OF LEVOCETIRIZINE IN BLOOD PLASMA BY USING RP-HPLC
}

\author{
Sweety Khatri* \\ *Malhotra College of Pharmacy, Badwai, Bhopal, (MP) 462038
}

\begin{abstract}
A rapid, selective, precise and sensitive reverse phase high-performance liquid chromatography method was developed for the quantitative estimation of Levocetirizine Dihydrochloride (LD) in human plasma and pharmaceutical dosage form. Extraction of drug from plasma was done by employing optimized liquid-liquid extraction procedure. The sample was analyzed using acetonitrile: methanol: $20 \mathrm{mM}$ ammonium acetate buffer $\mathrm{pH}-5$ (25:55:20 \% v/v/v) as mobile phase. Chromatographic separation was achieved on Thermo C-18 column $(4.6 \times 250 \mathrm{~mm}, 5 \mu$ particle size) as stationary phase using isocratic elution (at a flow rate of $1 \mathrm{ml} / \mathrm{min})$. The peak was detected using UV-PDA detector set at $232 \mathrm{~nm}$ and the total time for a chromatographic separation was 8 min. The calibration curve obtained was linear $\left(r^{2}=0.9998\right)$ over the concentration range of $2-10 \mu \mathrm{g} / \mathrm{ml}$. Method was validated for precision, robustness and recovery. The limit of detection and limit of quantitation was 0.0057 and $0.174 \mu \mathrm{g} / \mathrm{ml}$ respectively. There was no significant difference between the amount of drug spiked in plasma and the amount recovered and plasma did not interfere in estimation. Thus, the proposed method is suitable for the analysis of LD in tablet dosage forms and human plasma.
\end{abstract}

Keywords: RP-HPLC, Levocetirizine Dihydrochloride, Human plasma, Liquid-liquid extraction

Article Info: Received 08 Sep, 2018; Review Completed 07 Oct 2018; Accepted 08 Oct 2018; Available online 15 Oct 2018

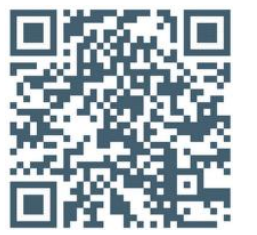

Cite this article as:

Khatri S, Bioanalytical method development and validation for the estimation of levocetirizine in blood plasma by using RP-HPLC , Journal of Drug Delivery and Therapeutics. 2018; 8(5-s):288-292 DOI: http://dx.doi.org/10.22270/jddt.v8i5-s.1977

Sweety Khatri, Malhotra College of Pharmacy, Badwai, Bhopal, (MP) 462038

\section{INTRODUCTION}

Levocetirizine dihydrochloride (LD, Fig.1), chemically is $\quad(2-[4-[(\mathrm{R})-(4-$ chlorophenyl $)$ henylmethyl $]-1-$ piperazinyl]ethoxy]-acetic acid dihydrochloride) is a third generation non sedative antihistamine ${ }^{1}$ and developed from the second generation antihistamine cetirizine. In many cases, the two racemic enantiomers differ in their pharmacokinetic and pharmacodynamic properties. Replacing existing recemates with single isomers has resulted in improved safety and/or efficacy profile of various recemates ${ }^{2,3}$. It works by blocking histamine receptors and polar in nature. LD has the advantages of higher efficacy, less side effects and longer duration over other antihistamines and has begun to replace cetirizine in clinical therapy stepwise. It has been chemically proved that the half dosage form of LD $(2.5 \mathrm{mg})$ has comparable antihistaminic activity to normal amount $(5.0 \mathrm{mg})$ of cetirizine in the treatment of allergic rhinitis and chronic idiopathic urticaria ${ }^{4,5}$. LD is official in Indian Pharmacopoeia ${ }^{6}$ and European Pharmacopoeia $^{7}$ this describes acid-base titration with $0.1 \mathrm{M} \mathrm{NaOH}$ in acetone/water medium. Literature survey revealed that $\mathrm{LD}$ has been reported to be determined by UV Spectrophotometry based on charge transfer reaction $^{8,9}$, LC-MS-MS ${ }^{10,11}$, RP-HPLC $^{12}$ and by HPTLC $^{13}$ in a variety of samples. LD in combination with a number of other drugs in tablet dosage form has been assayed by UV- spectrophotometry ${ }^{14,15}$, ratio derivative spectrophotometry ${ }^{16}$, TLC-densitometry ${ }^{17,18}$, Stability indicating ${ }^{19}$ and RP-HPLC ${ }^{20-25}$. However there is no method available for estimation of LD in human plasma By RP-HPLC Therefore, an attempt was made to develop a new, rapid and sensitive method for the determination of LD in human plasma. To access the reproducibility and wide applicability of the developed 
method, it was validated as per ICH norm, which is mandatory also ${ }^{26,27}$.<smiles>O=C(O)COCCN1CCN([C@@H](c2ccccc2)c2ccc(Cl)cc2)CC1</smiles>

Figure 1: Chemical structure of levocetirizine dihydrochloride

\section{EXPERIMENTAL}

\section{Materials}

The pure drug sample of LD $(99.56 \%)$ was obtained as gift sample from Reddy's Laboratory, Hyderabad. HPLC grade acetonitrile; methanol was purchased from Merck Ltd (Mumbai, India). All other chemicals and reagents used were of analytical grade. The human plasma was received from Peoples Hospital, Bhopal, MP, India. Triple distilled water was used throughout the process and prepared in-house; Liancet-L $(5 \mathrm{mg})$ Tablet was purchased from the local market.

\section{Equipments}

A high performance liquid chromatographic system from Waters comprising of manual injector, quaternary pump for constant flow and constant pressure delivery and Photodiode array detector connected to Ace software for controlling the instrumentation as well as processing the data generated was used. A thermo spectronic model of Lab India $3000+$ UV/VIS Spectrophotometer with $1 \mathrm{~cm}$. matched quartz cells was used for determination of $\lambda$ max.

\section{Chromatographic conditions}

The chromatographic analysis was performed by using a mobile phase of $20 \mathrm{mM}$ ammonium acetate buffer $(\mathrm{pH}$ $5.0)$, methanol and acetonitrile $(20: 55: 25 \mathrm{v} / \mathrm{v})$. These were filtered through $0.45 \mu$ membrane filter and degassed by sonication before use. The mobile phase was pumped isocratically at a flow rate of $1.0 \mathrm{ml} / \mathrm{min}$ during analysis at ambient temperature. The run time was set at $10 \mathrm{~min}$ and the volume of injection was $20 \mu \mathrm{l}$ and eluent was detected at $232 \mathrm{~nm}$ on a Thermo C-18 column $(4.6 \times 250 \mathrm{~mm}, 5 \mu$ particle size $)$ Fig. 2.

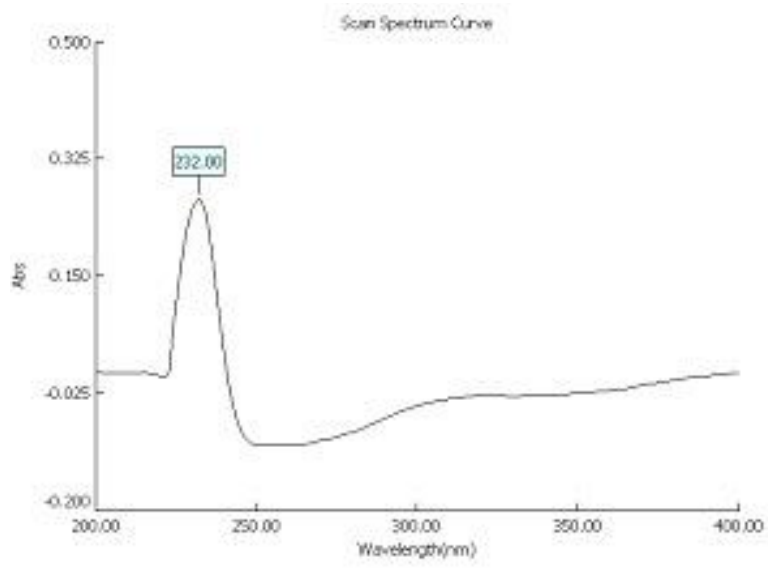

Figure 2: UV spectra of LD at $232 \mathrm{~nm}$

\section{Selection of mobile phase}

Initially to estimate LD number of mobile phase in different ratio were tried. Taking into consideration the system suitability parameter like RT, Tailing factor, No. of theoretical plates and HETP, the mobile phase found to be most suitable for analysis was acetonitrile: methanol: $20 \mathrm{mM}$ ammonium acetate buffer ( $\mathrm{pH}$ 5.0) in the ratio of $25: 55: 20 \mathrm{v} / \mathrm{v} / \mathrm{v}$. The mobile phase was filtered through $0.45 \mu$ filter paper to remove particulate matter and then degassed by sonication. Flow rate employed for analysis was $1.0 \mathrm{ml} / \mathrm{min}$.

\section{Preparation of standard stock solution}

Accurately weigh and transfer $10 \mathrm{mg}$ of LD of working standard into $50 \mathrm{ml}$ clean dry volumetric flask add about $40 \mathrm{ml}$ of diluents (Mobile Phase) and sonicate to dissolve it completely and make volume up to the mark with same solvent (Stock Solution). Further pipette $5 \mathrm{ml}$ of above stock solution in to a $10 \mathrm{ml}$ volumetric flask and dilute up to the mark with diluents. Further pipette 0.2 to $1.0 \mathrm{ml}$ of above stock solution into a $10 \mathrm{ml}$ volumetric flask and dilute up to the mark with diluents. This gives the solutions of $2-10 \mu \mathrm{g} / \mathrm{ml}$ for drug.

\section{Preparation of blank plasma}

To $1 \mathrm{ml}$ of plasma, $4 \mathrm{ml}$ of acetonitrile was added; the solution was mixed thoroughly and left to stand for 5 min at room temperature. After 5 min the solution was centrifuged at $10000 \mathrm{rpm}$ for $12 \mathrm{~min}$ at $4^{\circ} \mathrm{C}$. The clear supernatant liquid was removed, filtered through $0.22 \mu$ syringe filter and injected directly into HPLC system.

\section{Preparation of standard plasma stock solution}

To prepare calibration standards and quality control samples, appropriate quantities of the various diluted standard solutions added to blank plasma to obtain drugs in the concentrations range of $2-10 \mu \mathrm{g} / \mathrm{ml}$ for LD. These were stored at $-20^{\circ} \mathrm{C}$ and $20 \mu \mathrm{L}$ volume of each sample was injected and chromatographed.

\section{Assay in formulations}

To determine the content of the drug in the formulations, twenty marketed tablets of Liancet-L (Azillian Healthcare Pvt. Ltd., Ahmedabad) were weighed and ground to a fine powder; amount equal to $5 \mathrm{mg}$ of LD was taken in 50-ml volumetric flask before $50 \mathrm{ml}$ diluents was added. The content of the flask was shaken for about $60 \mathrm{~min}$. This solution was filtered through Whatman filter paper to separate out the insoluble excipients, and further dilutions were carried out to obtain the desired concentration. Final solutions were filtered through a $0.45-\mu \mathrm{m}$ Millipore filter before injection into the HPLC.

\section{RESULT AND DISCUSSION}

\section{Method validation}

The method was validated according to $\mathrm{ICH}$ guidelines such as linearity, precision, specificity, LOD, LOQ, accuracy and robustness. The linearity of this method was proved using linear correlation of the peak-area values and appropriate concentrations. 


\section{Linearity, limit of detection and quantification}

Under the previously described experimental conditions, linear correlation between the peak area and applied concentration was found in the concentration range 2-10 $\mu \mathrm{g} / \mathrm{ml}$. regression statistics are shown in Table 1. The LOD and LOQ at concentrations where the signal-to-noise ratios were equal to 3 and 10 respectively were determined to be $0.0057 \mu \mathrm{g} / \mathrm{ml}$ and $0.174 \mu \mathrm{g} / \mathrm{ml}$ for LD respectively. The correlation coefficient of this dependence was calculated to be 0.999 for LD.

Table 1 Regression statistics and LOD and LOQ

\begin{tabular}{|c|c|c|c|c|}
\hline Drug & Regression equation & $* \mathbf{r}^{2}$ & $* \mathbf{L O D}(\boldsymbol{\mu g} / \mathbf{m l})$ & $* \mathbf{L O Q}(\boldsymbol{\mu g} / \mathbf{m l})$ \\
\hline Levocetirizine & $\mathrm{y}=396.6 \mathrm{x}+24.80$ & 0.999 & 0.0057 & 0.174 \\
\hline
\end{tabular}

*Average of five determination

\section{Precision and robustness}

Precision of the methods was studied at three levels as at repeatability, intermediate precision (Day to Day and analyst to analyst) and reproducibility in synthetic samples using placebo mixtures. Mean \pm SD and \% relative standard deviation (RSD) values were used to express precision. As per ICH norms, small, but deliberate variations in concentration of the mobile phase were made to check the method's capacity to remain unaffected. The ratio of mobile phase was change from, ACN: methanol: ammonium acetate buffer $\mathrm{pH}-5 \quad(25: 55: 20 \quad \% \quad \mathrm{~V} / \mathrm{V} / \mathrm{V}), \quad$ to $(25: 54: 21 \%$ $\mathrm{V} / \mathrm{V} / \mathrm{V})$. Results of precision and robustness are reported in Table 2.

Table 2: Result of precision and robustness

\begin{tabular}{|c|c|c|}
\hline Validation Parameter & Percentage Mean \pm S.D*. $(\mathbf{n}=15)$ & Percentage RSD* $^{*}$ \\
\hline Repeatability & $99.23 \pm 0.09$ & 0.097 \\
\hline Reproducibility & $97.40 \pm 0.07$ & 0.078 \\
\hline Intermediate precision & $97.24 \pm 0.17$ & 0.179 \\
\hline Day to Day & $97.11 \pm 0.13$ & 0.144 \\
\hline Analyst to Analyst & $96.87 \pm 0.10$ & 0.110 \\
\hline \multicolumn{2}{|c|}{ Robustness* } \\
\hline
\end{tabular}

\section{Accuracy}

The accuracy of the proposed methods was assessed by recovery studies at three different levels i.e. $80 \%, 100 \%$ and $120 \%$. The recovery studies were carried out by adding a definite concentration of standard drug $(80 \%$, $100 \%$, and $120 \%$ ) to preanalyzed sample solutions. The resulting solutions were then re-analyzed by proposed methods. The value of mean recoveries was found to be in ranging from 97.76 to 99.88 for LD. Total amount of drug found and percentage recovery was calculated. Result of recovery studies are reported in Table 3.

Table 3: Results from recovery studies of levocetirizine

\begin{tabular}{|c|c|c|}
\hline Recovery Level \% & \multicolumn{2}{|c|}{ Levocetirizine } \\
\hline & \% Mean \pm SD* & \% RSD* \\
\hline $\mathbf{8 0}$ & $99.88 \pm 0.106$ & 0.106 \\
\hline $\mathbf{1 0 0}$ & $97.76 \pm 1.317$ & 1.347 \\
\hline $\mathbf{1 2 0}$ & $99.35 \pm 0.160$ & 0.161 \\
\hline \multicolumn{3}{|c}{ *Average of five determination }
\end{tabular}

Specificity

A representative chromatogram (Fig. 3) was generated to show that other components, which could be present in the sample matrix, are resolved from the parent analyte. No significant changes in retention times of the drugs in the presence and the absence of excipients clearly indicated the specificity of the method.

\section{Application in human Plasma}

It was observed after spiking the analyte in the plasma sample that there was no significant difference between the amount of drug spiked in plasma and the amount recovered. The recovery values (Table 4) in human plasma clearly indicate the applicability of the present method for the required purpose (Fig. 3).

Table 4: Accuracy and precision in human plasma

\begin{tabular}{|c|c|c|c|}
\hline Analyte & $\begin{array}{c}\text { Spiked } \\
\text { conc. } \\
(\boldsymbol{\mu g} / \mathbf{m l})\end{array}$ & $\begin{array}{c}\text { Precision } \\
(\boldsymbol{\%} \text { RSD })\end{array}$ & $\begin{array}{c}\text { Accuracy } \\
(\boldsymbol{\%})\end{array}$ \\
\hline Levocetirizine & $\mathbf{2}$ & 0.92 & 99.60 \\
\cline { 2 - 4 } & $\mathbf{4}$ & 1.02 & 98.56 \\
\cline { 2 - 4 } & $\mathbf{6}$ & 1.50 & 98.45 \\
\hline
\end{tabular}

*Average of five determination 


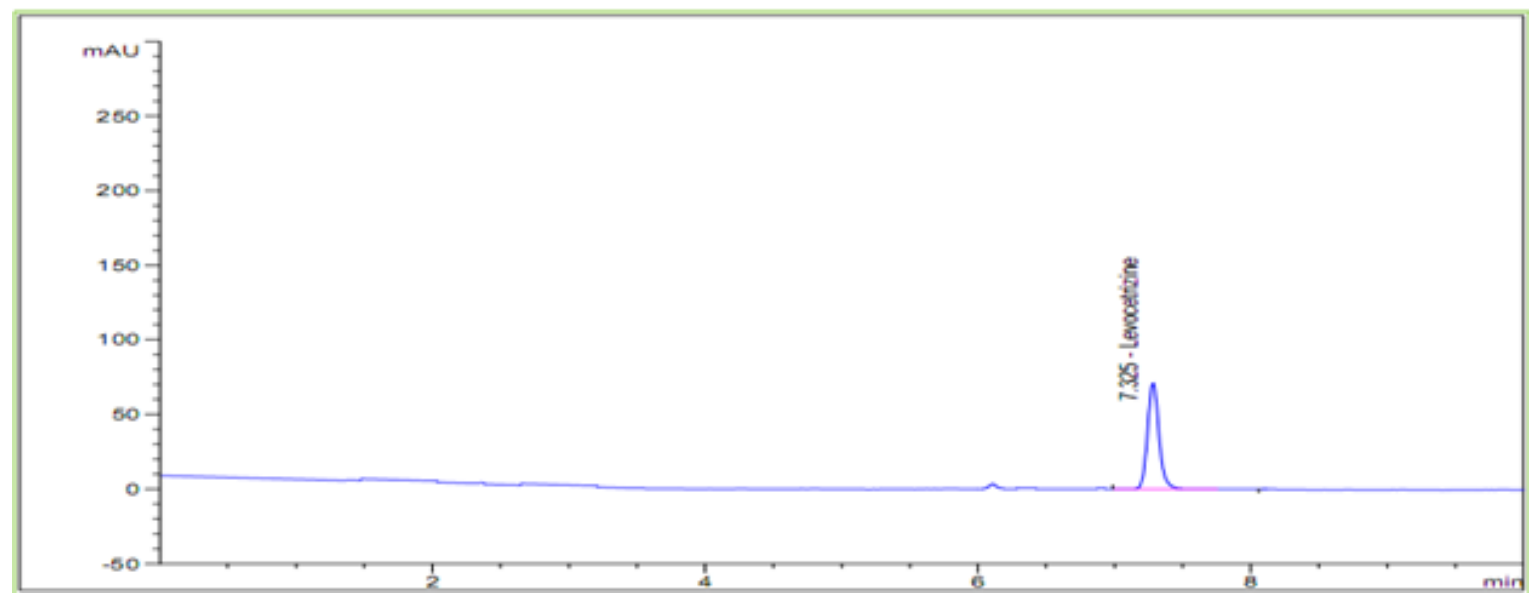

(A)

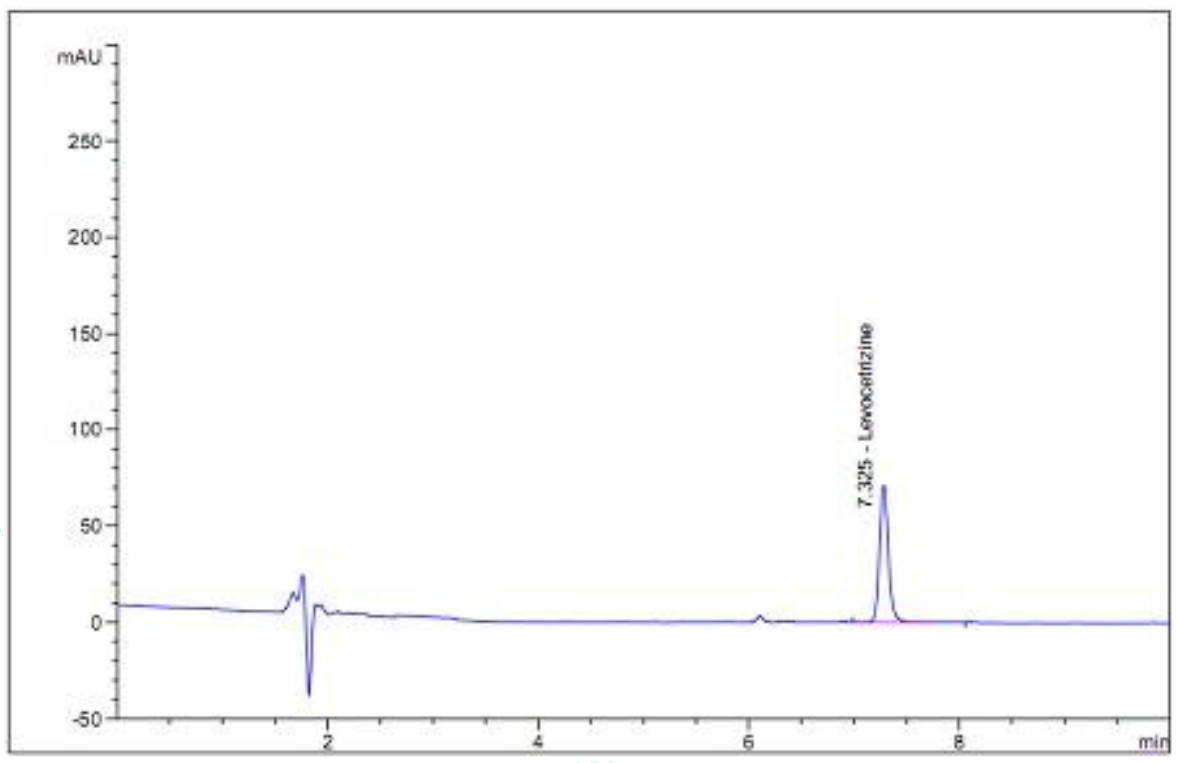

(B)

Figure 3: Representative chromatogram of LD in formulation (A), in human plasma (B).

\section{CONCLUSION}

All the results obtained by HPLC studies, it was concluded that the present method was fast and easy to perform. The linearity range, precision, accuracy, robustness, LOD, LOQ and specificity were processed to establish the suitability of the method and the confirmed results were obtained. HPLC has several superiorities compared with UV spectrophotometry, such as smaller detection and quantification limits, small sample volumes and specificity. Thus, the developed HPLC method is rapid, reliable, cost-effective and can be proposed for routine analysis laboratories and quality control purposes and are very beneficial for pharmaceutical companies, clinicians and physicians and also can be beneficial for the studies of drug interaction with other combinations.

\section{Conflict of interests}

The authors declare that there is no conflict of interests regarding the publication of this paper. 


\section{REFERENCES}

1. Neil JO. The Merck Index. $13^{\text {th }}$ ed.; Merck Research Laboratories, Merck and Co. Inc., Maryndale, White House Station, New Jersey, 2001.

2. Patil PA, Kothekar MA. Development of safer molecules through chirality, Indian Journal of Medical Sciences, 2006; 60(10):427-437.

3. Testa B, Trager WF. Racemates versus enantiomers in drug development: dogmatism or pragmatism, Chirality, 1990; 2(3):129-133.

4. Devalia JL, Hanotte F, Baltes E, Vos CD. A randomized, double-blind, crossover comparison among cetirizine, levocetirizine and ucb 28557 on histamine-induced cutaneous responses in healthy adult volunteers, Allergy, 2001; 56(1):50-57.

5. Grant JA, Riethuisen JM, Moulaert B, Vos CD. A doubleblind, randomized, single-dose, crossover comparison of levocetirizine with ebastine, fexofenadine, loratadine, mizolastine, and placebo: suppression of histamine-induced wheal-and-flare response during 24 hours in healthy male subjects, Annals of Allergy, Asthma \& Immunology, 2002; 88(2):190-197.

6. Indian Pharmacopoeia, Vol. II, The controller of Publications, Ministry of Health and Family Welfare: Govt. of India, New Delhi: 2007; p 1290.

7. European Pharmacopoeia, 6.0, Vol. II, EDQM, Council of Europe: Stranbourg, France: 2008; p 1479.

8. Raghu MS, Basavaiah K. Optimized and validated spectrophotometric methods for the determination of levocetirizine in pharmaceuticals based on charge transfer reaction, Journal of the Association of Arab Universities for Basic and Applied Sciences, 2012; 12:33-41.

9. Basavaiah K, Raghu MS, Vinay KB. Simple and rapid spectrophotometric assay of levocetirizine in pharmaceuticals through charge-transfer complexation using chloranilic acid and 2,3-dichloro-5,6-dicyanoquinone as $\pi$-acceptors, Bulletin of the Chemical Society of Ethiopia, 2012; 26(3):319-328.

10. Gunasakaran S, Rao N, Arunkumar R, Olaganathan A. Determination of levocetirizine in human plasma by liquid chromatography electrospray tandem mass spectrometry, Biomirror, 2010; 1(3):12-27.

11. Morita MR et al. Determination of levocetirizine in human plasma by liquid chromatography-electrospray tandem mass spectrometry: Application to a bioequivalence study, Journal of Chromatography B, 2008; 862:132-139.

12. Chaitanya Prasad MK, Vidyasagar G, Sambasiva Rao KRS, Induri M, Ramanjeneyulu S. Development of validated liquid chromatographic method for estimation of levocetirizine from pharmaceutical dosage forms, Journal of Applied Pharma Sciences, 2011; 01(10):95-97.

13. Bhusari VK, Dhaneshwar SR. Application of a stabilityindicating TLC method for the quantitative determination of Levocetirizine in pharmaceutical dosage forms, International Journal of Advance Pharma Sciences, 2010; 1:387-394.

14. Prabhu SL, Shirwaikar AA, Shirwaikar A, Kumar CD, Kumar GA. Simultaneous UV spectrophotometric estimation of ambroxol hydrochloride and levocetirizine dihydrochloride, Indian Journal of Pharma Sciences, 2008; 70(2):236-238.

15. Merukar SS, Mhaskar PS, Bavaskar SR, Burade KB, Dhabale PN. Simultaneous spectrophotometric methods for estimation of levocetirizine and pseudoephedrine in pharmaceutical tablet dosage form, Journal of Pharma Sciences and Research, 2009; 1(2):38-42.

16. Choudhari V, Kale A, Abnawe S, Kuchekar B, Gawli V, Patil N. Simultaneous determination of montelukast sodium and levocetirizine dihydrochloride in pharmaceutical preparations by ratio derivative spectroscopy, International Journal of Pharma Tech and Research, 2010; 2(1):4-9.

17. Smita S, Sharma MC, Kohli DV, Sharma AD. Development and validation of TLC-densitometry method for simultaneous quantification of montelukast sodium and levocetirizine dihydrochloride pharmaceutical solid dosage form, Der Pharmacia Lettre, 2010; 2(1):489-494.

18. Khedkar AN, Veer SU, Rakh MS, Rao JR. Simultaneous estimation and validation of levocetirizine, pseudoephedrine and ambroxol in bulk and combined tablet dosage form by HPTLC, International Journal of Pharmaceutical Quality Assurance, 2014; 6(1):2431.

19. Venkateswari P et al. Development of stability indicating RPHPLC method for the simultaneous estimation of ambroxol hydrochloride and levocetirizine dihydrochloride, International Journal of Advances in Pharmaceutical Sciences,2012; 2(2):34-40.

20. Ashok Kumar S, Senthil RM, Perumal P. RP-HPLC method development and validation for simultaneous estimation of montelukast sodium and levocetirizine dihydrochloride, International Journal of Pharmaceutical Research, 2009; 1:812 .

21. Ambadas RR, Vaishali SN. Determination of montelukast sodium and levocetirizine dihydrochloride in combined pharmaceutical dosage form by RP-HPLC, Latin American Journal of Pharmacy, 2010; 29(6):1020-1023.

22. Kamarapu SK, Vaijayanthi Bahlul ZEA, Venisetty RK. Development of RP-HPLC method for the analysis of levocetirizine dihydrochloride and ambroxol hydrochloride in combination and its application, International Journal of Pharmaceutical Sciences and Nanotechnology 2010; 3(1):893-897.

23. Shaikh KA, Patil AT. A stability-indicating LC method for the simultaneous determination of levocetirizine dihydrochloride and pseudoephedrine sulfate in tablet dosage forms, International Journal of Chem Tech Research, 2010; 2(1):454-461.

24. Ishaq BM, Prakash KV, Mohan GK, Muneer S, Ahad HA. RP-HPLC method for simultaneous estimation of levocetirizine dihydrochloride and montelukast sodium in tablets, Indian E-J. Pharma Sciences, 2015; 01(01):18-20.

25. Rao AS, Pavankumar KLNNSVK, Satyanarayana P, Sastrya GS. Validated reverse phase hplc method for the simultaneous estimation of guaifenesin, ambroxol and levocetirizine in pharmaceutical dosage forms, World Journal of Pharmacy and Pharmaceutical Sciences, 2015; 4(9):17351747.

26. Code Q2A-Text on Validation of Analytical Procedure Step3 Consensus Guideline, 1994, ICH Harmonised Tripartite Guideline.

27. Code Q2B- Validation of Analytical Procedure Methodology Step-4 Consensus Guideline, 1994, ICH Harmonised Tripartite Guideline. 